\title{
EDITORIAL
}

\section{Standing on the Shoulders of Giants: A Brief Note from the Perspective of Kinematics}

Chinese Journal of Mechanical Engineering (2017) 30: 1-2; DOI: 10.3901/CJME.2017.0101.001; published online January 1, 2017

Kinematics $^{[1-3]}$ has evolved with and contributed significantly to human demands. For example, slider-crank mechanisms have been widely used in engines since the industrial revolution. Additionally, constant-velocity shaft couplings have been developed to meet the needs of the automobile industry since the 1920's. With the development of robots, robot kinematics has been one of the research focuses in Kinematics since the 1970's. Several research areas in Kinematics, such as parallel mechanisms, compliant mechanisms, cable-driven parallel mechanisms, reconfigurable mechanisms, origami-inspired mechanisms, and biohybrid systems, have emerged in the past three decades.

The development of Kinematics has been closely related to mathematics and machine design. Recent advances in computer algebraic geometry and numerical algebraic geometry ${ }^{[4-5]}$ have enabled in-depth analysis of multi-mode parallel mechanisms ${ }^{[5-6]}$ which requires solving polynomial equations with positive dimensional solution sets. Now, advances in software engineering, artificial intelligence, biomimetics, materials, sensing, actuation, control, and manufacturing technologies are expected to have significant impact on Kinematics in the future. For instance, the application of mechanical CAD software can free people from deriving complicated mathematical equations in solving certain kinematic problems ${ }^{[7-8]}$.

In the following, two cases will be presented to illustrate the importance and challenges in maintaining awareness of the state-of-the-art of research in Kinematics and certain topics, which may involve old references in addition to the recent ones.

The first case pertains to the closed-form determination of the crank position corresponding to the maximum slider velocity in a slider-crank mechanism. This is a fundamental problem in engine design. Although slider-crank mechanisms have been used for centuries ${ }^{[9]}$, the above problem had not been solved until the publication of Refs. [10-12] at the end of the 19th century. In these publications, a cubic equation was derived using analytic or geometric approaches and then solved to obtain the crank position. However, these references were ignored for many years. This led to the publication of an alternative closed-form solution of the same problem in Ref. [13] in 1941. Refs. [10-13] were not known to the authors of Ref. [14], in which the slide-crank mechanism was taken as an example of the application of their approach to the analysis of four-bar linkages. Unaware of the work of Refs. [10-14], a numerical solution was presented in Ref. [15] in 1958 where the work of Refs. [10-14] was pointed out in the discussion by the reviewers. Without knowing the work of Refs. [10-13, 15] and based on the work of Ref. [14], a third closed-form solution was proposed in Ref. [16] in 2006 to replace the approximate solutions to this problem in textbooks. This was more than one hundred years after the publication of Refs. [10-12]. If the authors of Refs. [13-16] had known the previous work in Refs. [10-12], they could have saved both time and effort in finding their solutions. Possible causes of the unawareness of the Refs. [10-12] might include: (a) It was not easy to access the information about these old references at that time; and (b) Some of the terminology used in Refs. [10-12] was different from that in Refs. [13-16].

The second case concerns the type synthesis of parallel mechanisms. In the first decade of the 21 st century, several systematic approaches to the type synthesis of parallel mechanisms were proposed using different mathematical tools around the world ${ }^{[17-30]}$. However, the work on the constant-velocity shaft coupling connecting parallel axes by HUNT K $\mathrm{H}^{[31]}$ published in 1973 was ignored by almost all the researchers on parallel mechanisms, although it was closely related to the type synthesis of non-overconstrained translational parallel mechanisms. The ignorance of HUNT's work might have been caused by (a) It was on a different topic from parallel mechanisms; (b) HUNT himself did not mention his work $^{[31]}$ on the constant-velocity coupling in his paper $^{[32]}$ on the type synthesis of parallel mechanisms, which was based on the mobility equation; and (c) Not many people understood screw theory before 2000. Although the approach presented in Ref. [31] was used to obtain a new translational parallel mechanism in $2000^{[33]}$, Ref. [31] was only brought to the attention of more researchers on parallel mechanisms during The Workshop on Fundamental Issues and Future Research Directions for Parallel Mechanisms and Manipulators held in Canada in October 2002 when BROGARDH T made some people aware of the videos of HUNT's lectures about theory of constant-velocity shaft coupling, screw theory and robotics at ABB in 1997. Thanks to WU Yuanqing, these rare videos have been freely accessible online since 2015. If researchers had known the work of Ref. [31] earlier, they would have saved much time in reinventing the 3-DOF translational parallel mechanisms. Fortunately, such ignorance led to the development of several systematic methods on type synthesis using different approaches ${ }^{[17-30]}$ and the invention of a large number of parallel mechanisms. It is also noted in 1960's, 
HUNT K H and PHILLIPS J R revived the screw theory published in 1900 by R S BALL.

The above cases have demonstrated the significant impact of having awareness of the state-of-the-art in the relevant areas on the research in Kinematics. Although access to the literature has become more convenient than ever before, it is even more challenging to have full awareness of the state-of-the-art compared with decades ago when it was not easy to get the references one needed. This is because there are now so many emerging areas of research and technologies combined with a large number of new conference and journal publications. In addition to individual effort, collaboration within the same discipline and across different disciplines may provide a potential solution to meet this challenge.

\section{KONG Xianwen Associate Editor School of Engineering and Physical Sciences Heriot-Watt University Edinburgh EH14 4AS,UK}

\section{References}

[1] ERDMAN A G. Modern kinematics: Developments in the last forty years[M]. New York: Wiley-Interscience, 1993.

[2] McCarthy J M. 21st century kinematics[M]. London: Springer, 2013.

[3] DING X, KONG X, DAI J S. Advances in reconfigurable mechanisms and robots $I I[\mathrm{M}]$. Switzerland: Springer International Publishing, 2016.

[4] WALTER D R, HUSTY M L, PFURNER M. Chapter A: complete kinematic analysis of the SNU 3-UPU parallel manipulator[C]// BATES D J, BESANA G, Di ROCCO S, et al, eds, Interactions of Classical and Numerical Algebraic Geometry, Providence: American Mathematical Society, 2009: 331-346.

[5] SOMMESE A J, WAMPLER II C W. The numerical solution of systems of polynomials arising in engineering and science $[\mathrm{M}]$. Singapore: World Scientific, 2005.

[6] KONG X. Reconfiguration analysis of a 3-DOF parallel mechanism using Euler parameter quaternions and algebraic geometry method[J]. Mechanism and Machine Theory, 2014, 74: 188-201.

[7] SCHMIEDELER J P, CLARK B C, KINZEL E C, et al. Kinematic synthesis for infinitesimally and multiply separated positions using geometric constraint programming[J]. Journal of Mechanical Design, 2014, 136(3): 034503.

[8] JOHNSON A, KONG X, RITCHIE J M. Determination of the workspace of a three-degrees-of-freedom parallel manipulator using a three-dimensional computer-aided-design software package and the concept of virtual chains[J]. Journal of Mechanisms and Robotics, 2016, 8(2): 024501.

[9] SEAWARD J. Remarks on the comparative advantages of long and short connecting rods and long, and short stroke engines[J]. Minutes of the Proceedings of the Institution of Civil Engineers, 1841, 1: 53-55.

[10] HIL1 M J M. The problem of the connecting rod[J]. Minutes of the Proceedings of the Institution of Civil Engineers, 1896, 124: 390-401.

[11] UNWIN W C. Determination of crank angle for greatest piston velocity[J]. Minutes of the Proceedings of the Institution of Civil Engineers, 1896, 125: 363-366.
[12] BURLS G A. Note on maximum crosshead velocity[J]. Minutes of the Proceedings of the Institution of Civil Engineers, 1898, 131: 338-346.

[13] VOGEL W F. Crank mechanism motions: New methods for their exact determination-IIIJ]. Production Engineering, 1941, 12(8): 423-428.

[14] FREUDENSTEIN F. On the maximum and minimum velocities and the accelerations in four-link mechanisms[J]. Transactions of ASME, 1956, 78: 779-787.

[15] CHING-U IP, PRICE L C. A simple formula for determining the position of maximum slider velocity in a slider-crank mechanism[J]. Transactions of ASME, 1958, 80: 415-418.

[16] ZHANG W J, LI Q. A closed-form solution to the crank position corresponding to the maximum velocity of the slider in a centric slider-crank mechanism[J]. Journal of Mechanical Design, 2006, 128(2): 654-656.

[17] FRISOLI A, CHECCACCI D, SALSEDO F, et al. Synthesis by screw algebra of translating in-parallel actuated mechanisms[C]// LENARCIC J, STANISIC M M, eds, Advances in Robot Kinematics, Norwell: Kluwer Academic Publishers, 2000: 433-440.

[18] LI Q, HUANG Z, HERVE J M. Type synthesis of 3R2T 5-DOF parallel mechanisms using the Lie group of displacements[J]. IEEE Transactions on Robotics and Automation, 2004, 22(2): 173-180.

[19] ANGELES J. The qualitative synthesis of parallel manipulators[J]. Journal of Mechanical Design, 2004, 126(4): 617 -624.

[20] HUANG Z, LI Q, DING H. Theory of parallel mechanisms[M]. Dordrecht: Springer, 2013.

[21] FANG Y, TSAI L W. Analytical identification of limb structures for translational parallel manipulators[J]. Journal of Robotic Systems, 2004, 21(5): 209-218.

[22] KONG X, GOSSELIN C. Type synthesis of parallel mechanisms [M]. Berlin: Springer, 2007.

[23] ZHAO T, DAI J S, HUANG Z. Geometric synthesis of spatial parallel manipulators with fewer than six degrees of freedom[J]. Proceedings of the Institution of Mechanical Engineers, Part C: Journal of Mechanical Engineering Science, 2002, 216(12): 1175-1185.

[24] YANG T L, LIU A X, LUO Y F, et al. Theory and application of robot mechanism topology[M]. Beijing: Science Press, 2012. (in Chinese).

[25] GOGU G. Structural synthesis of parallel robots: Part 1methodology $[\mathrm{M}]$. Dordrecht: Springer, 2009

[26] HE J, GAO F, MENG X, et al. Type synthesis for 4-DOF parallel press mechanism using $\mathrm{G}_{\mathrm{F}}$ set theory[J]. Chinese Journal of Mechanical Engineering, 2015, 28(4): 851-859.

[27] MENG J, LIU G F, LI Z X. A geometric theory for analysis and synthesis of sub-6 DoF parallel manipulators[J]. IEEE Transactions on Robotics, 2007, 23: 625-649.

[28] LIU X J, WANG J. Parallel kinematics: Type, kinematics, and optimal design $[\mathrm{M}]$. Berlin: Springer, 2014.

[29] ZHAO J, FENG Z, CHU F, et al. Advanced theory of constraint and motion analysis for robot mechanisms[M]. Oxford: Elsevier, 2014.

[30] KONG X, GOSSELIN C M. Type synthesis of three-degreeof-freedom spherical parallel manipulators[J]. The International Journal of Robotics Research, 2004, 23(3): 237-245.

[31] HUNT K H. Constant-velocity shaft couplings: A general theory[J]. Journal of Engineering for Industry, 1973, 95(2): 455-464.

[32] HUNT K H. Structural kinematics of in-parallel-actuated robot-arms[J]. Journal of Mechanisms, Transmissions and Automation in Design, 1983, 105(4): 705-712.

[33] BROGARDH T. Design of high performance parallel arm robots for industrial applications[C]//Proceedings of $A$ Symposium Commemorating the Legacy, Works, and Life of Sir Robert Stawell Ball Upon the 100th Anniversary of A Treatise on the Theory of Screws, Cambridge, UK, July 9-12, 2000: Ball2000-15. 